\title{
Determination of the Relative and Absolute Configurations of the Female-produced Sex Pheromone of the Cerambycid Beetle Prionus californicus
}

\author{
Joshua Rodstein • Jocelyn G. Millar • James D. Barbour • J. Steven McElfresh • \\ Ian M. Wright • Karen S. Barbour • Ann M. Ray • Lawrence M. Hanks
}

Received: 1 October 2010 /Revised: 10 November 2010 /Accepted: 18 November 2010 / Published online: 3 December 2010

(C) The Author(s) 2010. This article is published with open access at Springerlink.com

\begin{abstract}
We previously identified the basic structure of the female-produced sex attractant pheromone of the cerambycid beetle, Prionus californicus Motschulsky (Cerambycidae: Prioninae), as 3,5-dimethyldodecanoic acid. A synthesized mixture of the four stereoisomers of 3,5-dimethyldodecanoic acid was highly attractive to male beetles. Here, we describe stereoselective syntheses of three of the four possible stereoisomers, and the results of laboratory and field bioassays showing that male beetles are attracted specifically to $(3 R, 5 S)-3,5$-dimethyldodecanoic acid, but not to its enantiomer, $(3 S, 5 R)$-3,5-dimethyldodecanoic acid, indicating that the $(3 R, 5 S)$-enantiomer is the active pheromone component. The diastereomeric $(3 R, 5 R)$ - and $(3 S, 5 S)$-enantiomers were excluded from consideration because their gas chromatographic retention times were
\end{abstract}

J. Rodstein · J. G. Millar

Department of Chemistry, University of California,

Riverside, CA 92521, USA

J. G. Millar $(\bowtie) \cdot J$. S. McElfresh • I. M. Wright

Department of Entomology, University of California,

Riverside, CA 92521, USA

e-mail:millar@ucr.edu

J. D. Barbour · K. S. Barbour

Southwest Idaho Research and Extension Center,

University of Idaho,

Parma, ID 83660-9637, USA

A. M. Ray · L. M. Hanks

Department of Entomology,

University of Illinois at Urbana-Champaign,

Urbana, IL 61801, USA

Present Address:

A. M. Ray

Department of Biology, Xavier University,

Cincinnati, OH 45207, USA different from that of the insect-produced compound. The mixture of the four stereoisomers of 3,5-dimethyldodecanoic acid was as attractive to male $P$. californicus as the $(3 R, 5 S)$ enantiomer, indicating that none of the other three stereoisomers inhibited responses to the active enantiomer. Beetles responded to as little as $10 \mathrm{ng}$ and $10 \mu \mathrm{g}$ of synthetic 3,5dimethyldodecanoic acid in laboratory and field studies, respectively. Field studies indicated that capture rate did not increase with dosages of 3,5-dimethyldodecanoic acid greater than $100 \mu \mathrm{g}$. In field bioassays, males of a congeneric species, $P$. lecontei Lameere, were captured in southern California but not in Idaho.

Key Words Cerambycidae · Prioninae - Sex pheromone . (3R,5S)-dimethyldodecanoic acid

\section{Introduction}

Volatile male-produced sex or aggregation pheromones have been reported for an increasing number of cerambycid beetle species (Silk et al., 2007; Lacey et al., 2009; Millar et al., 2009, and references therein; Ray et al., 2009a, b), most of which are members of the subfamilies Aseminae and Cerambycinae (Monné and Hovore, 2005). Femaleproduced pheromones also have been identified for two species that formerly were placed in the Cerambycidae, Migdolus fryanus Westwood and Verperus xatarti Dufour (Leal et al., 1994; Boyer et al., 1997), but whose familylevel taxonomy is uncertain (Napp, 1994; Bense, 1995; Dong and Yang, 2003). Many cerambycid species in the subfamily Prioninae have morphological and behavioral traits that are associated with production of pheromones by females in other types of insects (Thornhill and Alcock, 1983; Gemeno and Schal, 2003), including more elaborate 
antennal structures in males than females, and a more sedentary nature in females than males (Summerland, 1932; Benham and Farrar, 1976; Santos Ferreira, 1980; Hovore, 1981). Moreover, males of some prionine species display behaviors indicative of responses to volatile pheromones produced by females (Rotrou, 1936; Edwards, 1961; Benham and Farrar, 1976; Gwynne and Hostetler, 1978).

The prionine species Prionus californicus Motschulsky, is broadly distributed in western North America and is an economically important pest of hop, Humulus lupulus L. (Urticales: Cannabaceae), in the northwestern United States (Bishop et al., 1984). Adult $P$. californicus are active during summer and early fall, and are crepuscular (Linsley, 1962). They are among the largest cerambycids in North America, ranging in body length from 2.5 to $4.5 \mathrm{~cm}$ (volumes indexed in Linsley and Chemsak, 1997). Adult females oviposit in soil near the base of living woody plants; larvae feed on roots and rhizomes, requiring 3-5 yr to complete development (Linsley, 1962).

We previously reported that female $P$. californicus produce a volatile sex pheromone associated with an eversible structure on the ovipositor, and that males are strongly attracted to this pheromone (Cervantes et al., 2006; Barbour et al., 2007). The basic structure of the pheromone was identified as 3,5-dimethyldodecanoic acid by gas chromatographic (GC) retention time and mass spectral matches with those of one of the two peaks in a synthetic standard composed of an approximately equal mixture of all four stereoisomers of this compound (Rodstein et al., 2009). In the work reported here, we determined that the biologically active stereoisomer is $(3 R, 5 S)$-dimethyldodecanoic acid and confirmed the activity of the synthetic pheromone in laboratory and field bioassays. We also showed that the mixture of stereoisomers is as active as the insect-produced enantiomer, indicating that the unnatural stereoisomers do not antagonize attraction to the natural enantiomer.

\section{Methods and Materials}

Source of Insects Larvae of P. californicus were collected in fall of 2007 from commercial hop yards in southwestern Idaho and reared to adulthood in a field plot at the Southwest Idaho Research and Extension Center (Canyon Co., ID, USA). Larvae were reared individually in 19-1 plastic buckets buried in the ground to within $\sim 10 \mathrm{~cm}$ of their tops. Each bucket had two $0.75 \mathrm{~cm}$ holes in the bottom for drainage, and buckets were filled with soil to $\sim 10 \mathrm{~cm}$ from the top. We collected late stage larvae $(5-7.5 \mathrm{~cm}$ long) from uprooted hop crowns, and buried each larva $\sim 10 \mathrm{~cm}$ deep in the soil in a bucket, with a section of fresh hop rhizome for food.
We cut back hop plants growing from rhizomes in the buckets in early spring 2008, and we fitted buckets with lids that had the centers replaced with aluminum screen. Each bucket was drip-irrigated $(8 \mathrm{l} / \mathrm{hr})$ for $10 \mathrm{~min}$ every other day. Adult beetles emerged in buckets in July 2008 and were collected and held individually in the laboratory in ventilated glass jars $\left(\sim 500-1000 \mathrm{ml} ; 22^{\circ} \mathrm{C}, 16: 8 \mathrm{hr} \mathrm{L}: \mathrm{D}\right)$. Males and females were unmated and held in separate growth chambers. Beetles used in bioassays were 1-14-dold, vigorous, and apparently healthy.

Syntheses of Stereoisomers of 3,5-Dimethyldodecanoic Acid Tetrahydrofuran was dried and purified by distillation from sodium-benzophenone ketyl under argon. Solutions of crude products were dried over anhydrous $\mathrm{Na}_{2} \mathrm{SO}_{4}$ and concentrated by rotary evaporation under reduced pressure, unless specified otherwise. Crude products were purified by flash or vacuum flash chromatography on 230-400-mesh silica gel. ${ }^{1} \mathrm{H}$ - and ${ }^{13} \mathrm{C}-\mathrm{NMR}$ spectra were recorded on a Varian INOVA-400 spectrometer (Palo Alto, CA, USA) (400 and $100.5 \mathrm{MHz}$, respectively), as $\mathrm{CDCl}_{3}$ solutions. Integer resolution mass spectra were obtained with a Hewlett-Packard (HP) 6890 GC (Avondale, PA) interfaced to an HP 5973 mass spectrometer (MS), in EI mode $(70 \mathrm{eV})$ with helium carrier gas. The GC was equipped with a DB5MS column $(25 \mathrm{~m} \times 0.20 \mathrm{~mm}$ ID $\times 0.25 \mu$ film $)$. Resolutions of enantiomers were attempted on a Cyclodex-B column $(30 \mathrm{~m} \times 0.3 \mathrm{~mm}$ ID, J\&W Scientific, Folsom, CA, USA) using isothermal conditions or temperature programs of $2-4^{\circ} \mathrm{C}$ per min. Optical rotations were measured in $\mathrm{CH}_{2} \mathrm{Cl}_{2}$ on a Perkin Elmer 241 polarimeter $(\mathrm{Na}$ and $\mathrm{Hg}$ lamps) (Perkin Elmer, Waltham, MA, USA) in a $1 \mathrm{ml}$ water-jacketed cell $(10 \mathrm{~cm}$ path length $)$ at $24^{\circ} \mathrm{C}$. All rotations were averaged over three or four measurements. IR spectra were taken as films on $\mathrm{NaCl}$ plates on a Bruker Equinox 55 FTIR instrument (Freemont, CA, USA).

Methyl (E)-2-Decenoate (2) (Fig. 1) (E)-2-decenoic acid (1) $(20.91 \mathrm{~g}, 123 \mathrm{mmol}$, Acros Organics, Morris Plains, NJ, USA) was dissolved in methanol $(82 \mathrm{ml})$ in a dry flask under argon at room temperature. Acetyl chloride $(1.74 \mathrm{ml}$, $25 \mathrm{mmol}$ ) was added carefully dropwise (vigorous reaction!), and the reaction stirred for $16 \mathrm{~h}$ and then quenched with aqueous sodium bicarbonate. The resulting mixture was extracted $\mathrm{x} 4$ with ether. The combined ether extracts were washed with brine, dried, and concentrated. The resulting oil was Kugelrohr distilled (oven temp. $\sim 87^{\circ} \mathrm{C}$, 1 Torr) to yield $14.95 \mathrm{~g}(81 \mathrm{mmol}, 66 \%)$ of methyl $(E)-2-$ decenoate (2). ${ }^{1} \mathrm{H}$ NMR $\left(400 \mathrm{MHz}, \mathrm{CDCl}_{3}\right): \delta 0.89$ (t, $J=$ $6.8 \mathrm{~Hz}, 3 \mathrm{H}), 1.29(\mathrm{~m}, 8 \mathrm{H}), 1.46(\mathrm{~m}, 2 \mathrm{H}), 2.16-2.23(\mathrm{~m}$, $2 \mathrm{H}), 3.73(\mathrm{~s}, 3 \mathrm{H}), 5.82(\mathrm{~d}, J=15.6 \mathrm{~Hz}, 1 \mathrm{H}), 6.98(\mathrm{dt}, J=$ 15.4, 7.0 Hz, 1 H). ${ }^{13} \mathrm{C}$ NMR $\left(100.5 \mathrm{MHz}, \mathrm{CDCl}_{3}\right): \delta 14.2$, $22.8,28.2,29.3$ (2C), 31.9, 32.4, 51.5, 120.9, 150.0, 167.4. 
Fig. 1 Synthesis of $(3 R, 5 S)-(+)-$ 3,5-dimethyldodecanoic acid. a) acetyl chloride, $\mathrm{MeOH} ; \mathrm{b}$ ) $\mathrm{MeMgBr}, \mathrm{CuI},(S)$-Tol-BINAP, $t$-butylmethyl ether; c) DIBAL-H, hexane; d) methyl (triphenylphosphoranylidene) acetate, THF; e) $\mathrm{MeMgBr}, \mathrm{CuI},(R)$-Tol-BINAP, $t$-butylmethyl ether; f) $\mathrm{KOH}$, $\mathrm{MeOH} / \mathrm{H}_{2} \mathrm{O}$

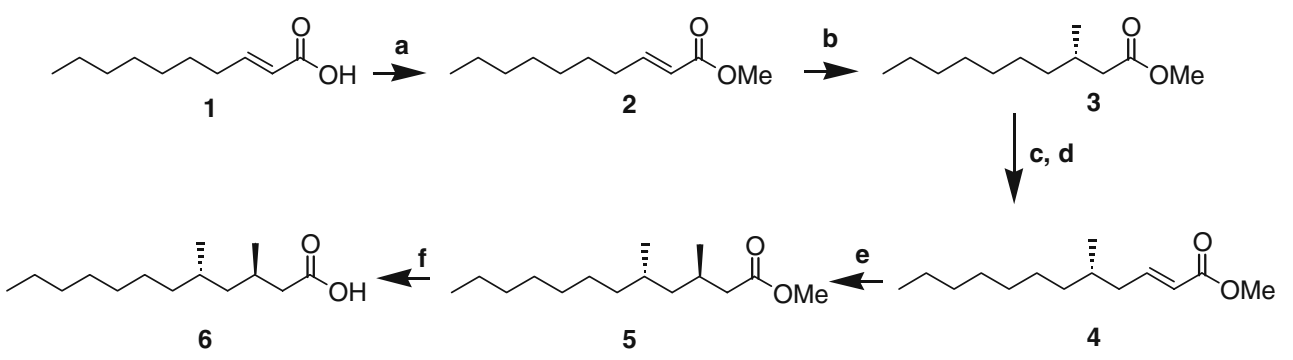

MS: $m / z(\%): 153\left(\mathrm{M}^{+}-31,3\right), 141$ (3), 110 (20), 96 (17), 87 (81), 69 (40), 55 (86). IR (film): 2953, 2928, 2856, $1728,1658,1460,1436,1378,1313,1270,1197,1170$, $1127,1041,979,921,854,720 \mathrm{~cm}^{-1}$.

Methyl (S)-(-)-3-Methyldecanoate (3) (S)-(-)-2,2'-Bis(di-ptolylphosphino)-1,1'-binaphthyl (= $(S)$-Tol-BINAP, $0.45 \mathrm{~g}$, $0.66 \mathrm{mmol}$; Alfa Aesar, Ward Hill, MA, USA) and CuI (84 mg, $0.44 \mathrm{mmol}$ ) were added to a dry three-neck flask charged with $\mathrm{CH}_{2} \mathrm{Cl}_{2}(55 \mathrm{ml})$ under argon. After stirring $30 \mathrm{~min}$, the $\mathrm{CH}_{2} \mathrm{Cl}_{2}$ was removed in vacuo and replaced with $t$-BuOMe $(27 \mathrm{ml})$, and the mixture stirred for $30 \mathrm{~min}$. The $t$-BuOMe was removed in vacuo and the resulting neon green-yellow solid diluted with a second portion of $t$ BuOMe $(88 \mathrm{ml})$. The mixture then was cooled to $-20^{\circ} \mathrm{C}$ and $\mathrm{MeMgBr}$ (38.3 ml, 2.4 M solution in $\left.\mathrm{Et}_{2} \mathrm{O}, 92 \mathrm{mmol}\right)$ added dropwise. After stirring for $20 \mathrm{~min}$, a solution of methyl (E)-2-decenoate $2(4.07 \mathrm{~g}, 22.1 \mathrm{mmol})$ in $t$-BuOMe $(27 \mathrm{ml})$ was added via syringe pump over $4.5 \mathrm{~h}$, maintaining the temperature at or slightly below $-20^{\circ} \mathrm{C}$. After stirring at $-20^{\circ} \mathrm{C}$ for another $2 \mathrm{~h}$, the reaction mixture was quenched with $\mathrm{MeOH}(10 \mathrm{ml})$, followed by saturated $\mathrm{NH}_{4} \mathrm{Cl}$ solution. The mixture was extracted with $\mathrm{Et}_{2} \mathrm{O}$ $(4 \times 75 \mathrm{ml})$ and the combined organic extracts were washed with brine, dried, and concentrated. The residue was purified by flash chromatography (hexane/EtOAc 97:3), then Kugelrohr distilled (oven temp. $\sim 92^{\circ} \mathrm{C}, 1$ Torr) yielding $2.39 \mathrm{~g}$ (11.9 mmol, 53\%) of methyl (S)-(-)-3methyldecanoate $(3) .[\alpha]_{\mathrm{D}}{ }^{20}=-4.2^{\circ}\left(\mathrm{c}=2.03, \mathrm{CH}_{2} \mathrm{Cl}_{2}\right) .{ }^{1} \mathrm{H}$ NMR (400 MHz, CDCl 3 ): $\delta 0.88(\mathrm{t}, J=6.7 \mathrm{~Hz}, 3 \mathrm{H}), 0.93$ $(\mathrm{d}, J=6.6 \mathrm{~Hz}, 3 \mathrm{H}), 1.26(\mathrm{~m}, 12 \mathrm{H}), 1.95(\mathrm{~m}, 1 \mathrm{H}), 2.09(\mathrm{~m}$, $1 \mathrm{H}), 2.31$ (dd, $J=14.7,6.0 \mathrm{~Hz}, 1 \mathrm{H}), 3.67(\mathrm{~s}, 3 \mathrm{H}) .{ }^{13} \mathrm{C}$ NMR (100.5 MHz, $\left.\mathrm{CDCl}_{3}\right): \delta 14.3,19.9,22.9,27.1,29.5$, 29.9, 30.6, 32.1, 36.9, 41.9, 51.5, 174.0. MS: $m / z(\%): 200$ $\left(\mathrm{M}^{+}, 1\right), 185$ (1), 169 (3), 157 (3), 143 (2), 101 (39), 87 (5), 74 (100), 55 (16), 43 (38). IR (film) 2957, 2928, 2855, $1732,1460,1437,1379,1167 \mathrm{~cm}^{-1}$.

Methyl (2E,5S)-(-)-5-Methyldodec-2-enoate (4) Methyl (S)(-)-3-methyldecanoate (3) (1.79 g, $8.93 \mathrm{mmol})$ was dissolved in hexane $(10 \mathrm{ml})$ in a dry flask under argon, and cooled to $-78^{\circ} \mathrm{C}$. Diisobutylaluminum hydride (DIBAL-H, $1 \mathrm{M}$ in hexane, $9.8 \mathrm{ml}, 9.8 \mathrm{mmol}$; Aldrich Chemical Co., Milwaukee, WI, USA) was added dropwise. The mixture

was stirred for $1 \mathrm{hr}$, and then another $1 \mathrm{ml}$ of DIBAL-H was added to reduce small amounts of residual starting material. After stirring another $30 \mathrm{~min}, \mathrm{MeOH}(1.13 \mathrm{ml})$ was added dropwise, and the mixture stirred for 30 min during which time a white suspension formed. Methyl (triphenylphosphoranylidene) acetate $(5.97 \mathrm{~g}, 17.9 \mathrm{mmol}$; Aldrich Chemical Co.) then was added at $-78^{\circ} \mathrm{C}$, followed by THF $(45 \mathrm{ml})$. The reaction was allowed to warm to room temperature overnight and stirred for an additional $48 \mathrm{~h}$. The mixture was diluted with $\mathrm{Et}_{2} \mathrm{O}(20 \mathrm{ml})$ and $6 \mathrm{M} \mathrm{HCl}$ $(40 \mathrm{ml})$, and stirred until two clear layers were observed. After separation of the organic layer, the aqueous phase was extracted $\mathrm{x} 3$ with $\mathrm{Et}_{2} \mathrm{O}$, and the combined organic extracts were washed with saturated aqueous $\mathrm{NaHCO}_{3}$ and brine, dried, and concentrated. The residue was taken up in hexane and filtered through a small plug of silica gel to remove the bulk of the triphenylphosphine oxide. The filtrate was concentrated and purified by flash chromatography (hexane/EtOAc 98:2 then 96:4). The product was purified further by Kugelrohr distillation (oven temp. $\sim 110^{\circ} \mathrm{C}$, 1 Torr) to yield methyl $(2 E, 5 S)-(-)-5$-methyldodec-2-enoate (4) $(1.01 \mathrm{~g}, 2.5 \mathrm{mmol}, 50 \%) \cdot[\alpha]_{\mathrm{D}}{ }^{20}=-1.3^{\circ}(\mathrm{c}=1.99$, $\left.\mathrm{CH}_{2} \mathrm{Cl}_{2}\right) .{ }^{1} \mathrm{H}$ NMR $\left(400 \mathrm{MHz}, \mathrm{CDCl}_{3}\right): \delta 0.88(\mathrm{t}, J=$ $6.4 \mathrm{~Hz}, 3 \mathrm{H}), 0.89(\mathrm{~d}, J=6.8,3 \mathrm{H}), 1.26(\mathrm{~m}, 12 \mathrm{H}), 1.60$ (m, $1 \mathrm{H}), 2.03(\mathrm{~m}, 1 \mathrm{H}), 2.20(\mathrm{~m}, 1 \mathrm{H}), 3.73(\mathrm{~s}, 3 \mathrm{H}), 5.81(\mathrm{~d}, J=$ $15.6 \mathrm{~Hz}, 1 \mathrm{H}), 6.95(\mathrm{~m}, 1 \mathrm{H}) .{ }^{13} \mathrm{C}$ NMR $(100.5 \mathrm{MHz}$, $\left.\mathrm{CDCl}_{3}\right): \delta 14.3,19.8,22.9,27.2,29.5,30.0,32.1,32.7$, 36.8, 39.9, 51.5, 122.1, 148.9, 167.3. MS: $m / z(\%): 195$ (2, $\left.\mathrm{M}^{+}-33\right), 155$ (1), 142 (5), 100 (100), 85 (11), 71 (21), 57 (27), 43 (60). IR (film) 3054, 2956, 2927, 2855, 2306, 1718, $1655,1437,1378,1322,1265,1195,1143,982,909$, $737 \mathrm{~cm}^{-1}$.

Methyl (3R,5S)-(+)-3,5-Dimethyldodecanoate (5) (R)-TolBINAP (54 mg, $0.08 \mathrm{mmol})$ and $\mathrm{CuI}(10 \mathrm{mg}, 0.053 \mathrm{mmol})$ were stirred in $\mathrm{CH}_{2} \mathrm{Cl}_{2}(10 \mathrm{ml})$ in a dry flask under argon. After $30 \mathrm{~min}$, the solvent was removed in vacuo and replaced with $t$-BuOMe $(10 \mathrm{ml})$, and the mixture stirred for $30 \mathrm{~min}$. The $t$-BuOMe was removed in vacuo, and the resulting green-yellow solid was resuspended in $t$-BuOMe $(10 \mathrm{ml})$. The mixture was cooled to $-20^{\circ} \mathrm{C}$ and $\mathrm{MeMgBr}$ $\left(5.4 \mathrm{ml}, 2.5 \mathrm{M}\right.$ solution in $\left.\mathrm{Et}_{2} \mathrm{O}, 13.5 \mathrm{mmol}\right)$ added dropwise. After stirring for $20 \mathrm{~min}$, a solution of methyl (2E,5S)-(-)-5-methyldodec-2-enoate (4) $(0.6 \mathrm{~g}, 2.6 \mathrm{mmol})$ 
in $t$-BuOMe $(3.2 \mathrm{ml})$ was added via syringe pump over $4.5 \mathrm{hr}$. After stirring at $-20^{\circ} \mathrm{C}$ for another $2 \mathrm{hr}$, the reaction mixture was quenched with $\mathrm{MeOH}(3 \mathrm{ml})$, followed by saturated $\mathrm{NH}_{4} \mathrm{Cl}$ solution. The mixture was extracted with $\mathrm{Et}_{2} \mathrm{O}(4 \mathrm{x})$, and the combined organic extracts were washed with brine, dried, and concentrated. The residue was purified by flash chromatography (hexane/EtOAc, 97:3), then Kugelrohr distillation (oven temp. $\sim 100^{\circ} \mathrm{C}, 1$ Torr) to yield $0.074 \mathrm{~g}(0.31 \mathrm{mmol}, 12 \%)$ of methyl $(3 R, 5 S)-(+)-3,5-$ dimethyldodecanoate (5) (diastereomeric purity $90.7 \%$ by GC). $[\alpha]_{\mathrm{D}}{ }^{20}=+16.0^{\circ}\left(\mathrm{c}=1.4, \mathrm{CH}_{2} \mathrm{Cl}_{2}\right) .{ }^{1} \mathrm{H}$ NMR $(400 \mathrm{MHz}$, $\mathrm{CDCl}_{3}$ ): $\delta 0.84(\mathrm{t}, J=6.8 \mathrm{~Hz}, 3 \mathrm{H}), 0.89(\mathrm{~d}, J=6.8 \mathrm{~Hz}, 3 \mathrm{H})$, $0.90(\mathrm{~d}, J=6.4 \mathrm{~Hz}, 3 \mathrm{H}), 1.12(\mathrm{~m}, 2 \mathrm{H}), 1.27(\mathrm{~m}, 12 \mathrm{H})$, 1.46 (br s, $1 \mathrm{H}), 2.08$ (m, $2 \mathrm{H}), 2.27$ (dd, $J=14.4,6.0 \mathrm{~Hz}$, $1 \mathrm{H}), 3.67(\mathrm{~s}, 3 \mathrm{H}) .{ }^{13} \mathrm{C}$ NMR $\left(100.5 \mathrm{MHz}, \mathrm{CDCl}_{3}\right)$ : $\delta 14.3,19.5,19.6,22.9,27.2,28.0,29.6,30.1,30.2,32.1$, 37.9, 42.6, 44.6, 51.5, 173.9. MS: $m / z(\%): 242\left(\mathrm{M}^{+}, 1\right)$, 227 (1), 211 (1), 185 (4), 169 (2), 157 (1), 143 (4), 125 (2), 115 (5), 101 (40), 83 (12), 74 (100), 55 (24), 43 (47). IR (film) 2957, 2927, 2854, 1733, 1461, 1436, 1379, 1191, $1007,910 \mathrm{~cm}^{-1}$.

(3R,5S)-(+)-3,5-Dimethyldodecanoic Acid (6) A mixture of methanol (1.1 ml), water $(1.2 \mathrm{ml}), \mathrm{KOH}(0.32 \mathrm{~g}, 5.2 \mathrm{mmol})$, and methyl $(3 R, 5 S)-(+)-3,5$-dimethyldodecanoate (5) $(70 \mathrm{mg}, 0.29 \mathrm{mmol}$ ) were stirred overnight at room temperature. The mixture was extracted with hexane, and the remaining aqueous layer acidified with $1 \mathrm{M} \mathrm{HCl}$ and extracted three times with $\mathrm{Et}_{2} \mathrm{O}$. The combined ether layers were washed with brine, dried, and concentrated, yielding $(3 R, 5 S)-(+)-3,5$-dimethyldodecanoic acid (6) $(54.2 \mathrm{mg}$, $82 \%) .[\alpha]_{\mathrm{D}}{ }^{20}=+18.1^{\circ} \quad\left(\mathrm{c}=1.08, \mathrm{CH}_{2} \mathrm{Cl}_{2}\right) .{ }^{1} \mathrm{H} \quad \mathrm{NMR}$ $\left(400 \mathrm{MHz}, \mathrm{CDCl}_{3}\right): \delta 0.87(\mathrm{~m}, 6 \mathrm{H}), 0.94(\mathrm{~d}, J=6.4 \mathrm{~Hz}$, $3 \mathrm{H}), 1.14$ (m, $2 \mathrm{H}), 1.27$ (m, $12 \mathrm{H}), 1.46$ (br s, $1 \mathrm{H}), 2.06$ (m, $1 \mathrm{H}), 2.17$ (dd, $J=14.8,8.0 \mathrm{~Hz}, 1 \mathrm{H}), 2.31$ (dd, $J=14.8$, $6.0 \mathrm{~Hz}, 1 \mathrm{H}) .{ }^{13} \mathrm{C}$ NMR $\left(100.5 \mathrm{MHz}, \mathrm{CDCl}_{3}\right): \delta 14.3$, 19.5, 19.6, 22.9, 27.2, 27.8, 29.5, 30.1, 30.2, 32.1, 37.9, 42.4, 44.5, 179.1. MS: $m / z(\%): 228\left(\mathrm{M}^{+}, 1\right), 171(8), 129$ (14), 111 (11), 101 (13), 87 (74), 69 (42), 57 (57), 43 (100). IR (film) 2958, 2925, 2872, 2854, 1709, 1463, 1410, 1379 , 1296, 1233, 1196, 937, $722 \mathrm{~cm}^{-1}$.

Methyl (R)-(+)-3-Methyldecanoate (7) This compound was prepared in analogous fashion to compound $\mathbf{3}$ from methyl (E)-2-decenoate (2), using $(R)-(+)-2,2^{\prime}$-bis(di-ptolylphosphino)-1,1'-binaphthyl $(=(R)$-Tol-BINAP $)$ as catalyst, yielding methyl $(R)-(+)-3$-methyldecanoate (7) in $49 \%$ isolated yield. $[\alpha]_{\mathrm{D}}{ }^{20}=+4.8^{\circ}\left(\mathrm{c}=2.02, \mathrm{CH}_{2} \mathrm{Cl}_{2}\right) .{ }^{1} \mathrm{H}$ NMR, ${ }^{13} \mathrm{C}$ NMR, IR, and mass spectra matched those of the $(S)$-enantiomer (3).

Methyl (2E,5R)-(+)-5-Methyldodec-2-enoate (8) This compound was made in analogous fashion to compound $\mathbf{4}$ by using methyl $(R)-(+)-3$-methyldecanoate (7) instead of the methyl $(S)-(-)-3$-methyldecanoate (3) to afford the desired $(E)$-alkenoate in $27 \%$ yield after purification. A further $41 \%$ of a mixture of the $(E)$ - and $(Z)$-isomers also was obtained. $[\alpha]_{\mathrm{D}}{ }^{20}=+1.8^{\circ}\left(\mathrm{c}=2.06, \mathrm{CH}_{2} \mathrm{Cl}_{2}\right)$. The ${ }^{1} \mathrm{H}$ NMR, ${ }^{13} \mathrm{C}$ NMR, IR, and mass spectra agreed with those of the (S)-enantiomer 4.

Methyl (3S,5R)-(-)-3,5-Dimethyldodecanoate (9) This enantiomer was made in analogous fashion to compound $\mathbf{5}$ in $23 \%$ isolated yield from methyl $(2 E, 5 R)-(+)-5$-methyl-2dodecenoate (8) (diastereoisomeric purity, 92.5\%), using $(S)$-Tol-BINAP instead of $(R)$-Tol-BINAP as catalyst. $[\alpha]_{\mathrm{D}}{ }^{20}=-18.2^{\circ}\left(\mathrm{c}=1.13, \mathrm{CH}_{2} \mathrm{Cl}_{2}\right) .{ }^{1} \mathrm{H}$ NMR, ${ }^{13} \mathrm{C} \mathrm{NMR}$, IR, and mass spectra matched those of the corresponding $(3 R, 5 S)-(+)$-enantiomer $(\mathbf{5})$.

(3S,5R)-(-)-3,5-Dimethyldodecanoic Acid (10) Methyl $(3 S, 5 R)-(-)-3,5$-dimethyldodecanoate (9) was hydrolyzed in similar fashion to compound $\mathbf{6}$, yielding $(3 S, 5 R)-(-)$ 3,5 -dimethyldodecanoic acid $(\mathbf{1 0})$ in $46 \%$ yield. $[\alpha]_{\mathrm{D}}{ }^{20}=$ $-19.2^{\circ}\left(\mathrm{c}=0.48, \mathrm{CH}_{2} \mathrm{Cl}_{2}\right) .{ }^{1} \mathrm{H}$ NMR, ${ }^{13} \mathrm{C} \mathrm{NMR}, \mathrm{IR}$, and mass spectra matched those of the corresponding $(3 R, 5 S)$ enantiomer (6).

Methyl (3S,5S)-(-)-3,5-Dimethyldodecanoate (11) This diastereomer was made in analogous fashion in $84 \%$ isolated yield from methyl (2E,5S)-(-)-5-methyl-2-dodecenoate (4) (diastereomeric purity, $97.5 \%$ by GC), using (S)-TolBINAP as catalyst for the asymmetric addition reaction. $[\alpha]_{\mathrm{D}}{ }^{20}=-2.2^{\circ}\left(\mathrm{c}=1.54, \mathrm{CH}_{2} \mathrm{Cl}_{2}\right) .{ }^{1} \mathrm{H}$ NMR $(400 \mathrm{MHz}$, $\left.\mathrm{CDCl}_{3}\right): \delta 0.87(\mathrm{t}, J=6.8 \mathrm{~Hz}, 3 \mathrm{H}), 0.91(\mathrm{~d}, \mathrm{~J}=9.2 \mathrm{~Hz}, 3 \mathrm{H})$, $0.93(\mathrm{~d}, J=6.4 \mathrm{~Hz}, 3 \mathrm{H}), 1.03(\mathrm{~m}, 2 \mathrm{H}), 1.27(\mathrm{~m}, 12 \mathrm{H})$, 1.45 (br, $1 \mathrm{H}), 2.05(\mathrm{~m}, 2 \mathrm{H}), 2.31(\mathrm{~m}, 1 \mathrm{H}), 3.67(\mathrm{~s}, 3 \mathrm{H})$. ${ }^{13} \mathrm{C}$ NMR $\left(100.5 \mathrm{MHz}, \mathrm{CDCl}_{3}\right): \delta 14.3,20.3,20.6$, $22.9,27.0,28.1,29.6,30.1,30.2,32.1,36.9,41.8,44.9$, 51.5, 174.0. MS: $m / z$ (\%): 242 (2), 227 (1), 211 (2), 185 (11), 166 (3), 143 (9), 125 (3), 111 (7), 101 (73), 83 (17), 74 (100), 55 (32), 43 (54). IR (film) 2966, 2906, 2848, 2257, 1740, 1464, 1441, 1373, 1165, 1010, 913, 838, $733 \mathrm{~cm}^{-1}$.

Laboratory Bioassays of Synthetic Pheromone We tested the responses of male $P$. californicus to synthetic pheromone using a rectangular olfactometer $(80 \times 10 \times 19.5 \mathrm{~cm}, \mathrm{~L} \times \mathrm{H} \times$ W) constructed of polyethylene with a removable glass top (see Cervantes et al., 2006). Both openings, at one end of the olfactometer were fitted with PVC female adapters $(3.75 \mathrm{~cm}$ diam), to which we attached containers $(17.8 \mathrm{~cm}$-long sections of $3.75 \mathrm{~cm}$ diam clear PVC pipe, covered with aluminum screen at one end, and the other end inserted into a screened PVC male adapter) that held sample or control odor sources. Air was pulled $\left(3.2 \mathrm{~m} . \mathrm{s}^{-1}\right)$ from outside the 
building through an activated charcoal filter, then through the sample containers and into the olfactometer chamber.

We conducted bioassays in July 2008 under a $25-\mathrm{W}$ incandescent red light to minimize the influence of visual signals, during the 2 nd to 6 th $\mathrm{hr}$ of scotophase, when adult beetles typically are active (Barbour et al., 2007). All males walked rather than attempting to fly in the olfactometer. A positive score was given to males that walked upwind and reached a sample container that held the pheromone lure within $5 \mathrm{~min}$. A negative score was given to those that reached the control container within $5 \mathrm{~min}$. Beetles that did not reach either container within 5 min were scored "no response". We washed the olfactometer with soap (1-2\% Micro- $90^{\circledR}$, Cole Parmer Instrument Co., Vernon Hills, IL, USA) and water after every five trials, then rinsed it with acetone, allowed it to air dry, and switched sample containers between sides to control for location effects. We tested at least five males against each treatment/dose and repeated the bioassays on at least $3 \mathrm{~d}$ ( $N \geq 15$ for each treatment).

We tested the response of male $P$. californicus to synthetic 3,5-dimethyldodecanoic acid in the olfactometer using 1,10 , or $100 \mathrm{ng}$ of material in $10 \mu \mathrm{l}$ hexane (HPLC grade, Chromasolv ${ }^{\circledR}$, Sigma-Aldrich, St. Louis, MO, USA). A filter paper disc (1.5 cm diam., Grade 413, VWR, West Chester, PA, USA) was placed on a piece of clean aluminum foil $\left(\sim 2.5 \mathrm{~cm}^{2}\right)$ and pheromone solution applied to the paper. The aluminum foil square and disc were placed into a randomly-selected sample container. A piece of aluminum foil and paper disc treated with $10 \mu \mathrm{l}$ of hexane (control) was placed in the other container. Bioassays on each day were conducted using the lowest dose $(1 \mathrm{ng})$ first, and then sequentially higher doses, so as to minimize any effects from contamination of the olfactometer by a previous treatment.

We compared the responses of males to $(3 R, 5 S)$ - and $(3 S, 5 R)$-dimethyldodecanoic acid in the olfactometer using the methods described above. We tested $0.25,2.5$, and $25 \mathrm{ng}$ of each enantiomer, corresponding to the approximate amount of each of the four stereoisomers in the 1,10 , and $100 \mathrm{ng}$ range of doses of 3,5-dimethyldodecanoic acid that previously had been tested. To further evaluate the activity of $(3 S, 5 R)$-dimethyldodecanoic acid, we ran bioassays using the lowest dose that had elicited a significant positive response from males to the $(3 R, 5 S)$-enantiomer (2.5 ng; see Results) tested against a solvent control. The two diastereomers, $(3 R, 5 R)$ - and $(3 S, 5 S)$-dimethyldodecanoic acid, were not tested in laboratory or field bioassays because their GC retention times were different from that of the insect-produced pheromone, conclusively eliminating them as candidates for the pheromone (see below). The mixture of four 3,5-dimethyldecanoic acid stereoisomers was synthesized as previously described (Rodstein et al.,
2009), and the syntheses of the stereoisomers are described above.

Field Bioassays of Synthetic Pheromone Field bioassays of 3,5-dimethyldodecanoic acid and (3R,5S)-dimethyldodecanoic acid were conducted in southern California and Idaho. Our primary study site in southern California was the Santa Rosa Plateau Ecological Reserve (SRPER; Riverside Co.), a 5,600-ha area with extensive stands of mature oaks (Quercus agrifolia Née and $Q$. engelmannii Greene), coastal sage scrub, and chaparral. Adult $P$. californicus are commonly attracted to lights at the visitor center (SRPER staff, pers. comm.). Field bioassays at SRPER were conducted 2-6 July 2008 (maximum air temperatures $28-35^{\circ} \mathrm{C}$, no precipitation). Field bioassays also were conducted in commercial hop yards (4-17 ha) in Canyon County, Idaho, that were naturally infested with $P$. californicus (unpub. data). Bioassays in Idaho were conducted 8-15 July 2008 (maximum air temperatures $28-36^{\circ} \mathrm{C}$, no precipitation).

Traps used in California consisted of $~ 1.9-1$ wide-mouth plastic jars (P.E.T.; model 55-650, General Bottle Supply Company, Los Angeles, CA, USA), fitted with a 1.9-1 plastic funnel, with the spout cut off to leave a $\sim 3.5 \mathrm{~cm}$ diam hole at the bottom. $\mathrm{A} \sim 3.5 \mathrm{~cm}$ diam hole was cut into the threaded lid of the jar, and the funnel spout inserted into the hole and glued in place so that the spout was inside the jar. We treated interior surfaces of funnels and jars with Rain- $\mathrm{X}^{\circledR}$ glass treatment (Houston, TX, USA) to render them slippery. Traps were buried so that the rim of the funnel was nearly flush with the ground and, as required, a ramp to the funnel rim was built from soil and leaf litter. Lures were suspended $\sim 15 \mathrm{~cm}$ over the trap with a stiff wire that was attached to the funnel. It was not possible to set up traps in linear transects at SRPER because of the abundant large rocks and boulders, so they were positioned arbitrarily under the canopy of oaks, at least $\sim 10 \mathrm{~m}$ apart.

Traps in Idaho consisted of 19-1 polypropylene buckets $(38 \mathrm{~cm}$ tall $\times 30 \mathrm{~cm}$ diam) fitted with aluminum funnels (model 2815B, BioQuip, Rancho Dominguez, CA, USA). Traps were buried $90 \mathrm{~m}$ apart, within rows of hop plants, with the tops of funnels flush with the soil surface. Lures were suspended over funnels by attaching them to the wire bucket handles, which had been modified to remain upright.

Lures for traps in both California and Idaho consisted of clear low density polyethylene press-seal bags (Bagette model 14770, $5.1 \times 7.6 \mathrm{~cm}, 0.05 \mathrm{~mm}$ wall thickness, Cousin Corp., Largo, FL, USA). Dilutions of synthetic pheromone or solvent were pipetted into the bags, which then were sealed. Experiments were set up in late afternoon or dusk, and treatments were assigned randomly to traps. Beetles were collected from traps the next morning or the morning 
of the second day. In both locations, captured beetles were released into vegetation, at least $25 \mathrm{~m}$ away from the nearest trap, immediately after they were collected from traps.

Treatments in bioassays conducted at SRPER in southern California were as follows: 3,5-dimethyldodecanoic acid (10 $\mathrm{mg}$ in $100 \mu \mathrm{l}$ hexane), (3R,5S)-dimethyldodecanoic acid ( $2.5 \mathrm{mg}$ in $100 \mu \mathrm{l}$ hexane), $(3 S, 5 R)$-dimethyldodecanoic acid ( $2.5 \mathrm{mg}$ in $100 \mu \mathrm{l}$ hexane), and control (100 $\mu$ l hexane). Treatments were assigned randomly to four traps in each of four blocks (at least $400 \mathrm{~m}$ apart) on 2 and 3 July 2008. We recorded the number of male $P$. californicus in traps (no females were captured), and rotated traps one position within blocks after the first day. Males of the congeneric species, Prionus lecontei Lameere, also were caught in traps at the southern California site, and trap captures recorded.

Lure doses in bioassays conducted in Idaho were as follows: 3,5-dimethyldodecanoic acid (1 $\mathrm{mg}$ in $100 \mu \mathrm{l}$ hexane), (3R,5S)-dimethyldodecanoic acid (250 $\mu \mathrm{g}$ in $100 \mu \mathrm{l}$ hexane), and control (100 $\mu \mathrm{l}$ hexane). We also included positive control traps, which were baited with a single live female $P$. californicus, to compare responses of males to natural versus synthetic pheromone. Unmated females were reared as described above, and were confined in a wire-mesh cage attached to the wire handle of trap buckets, analogous to the positioning of the synthetic lures. Treatments were randomized in each of four different hop yards on 14 July 2008. Captured males were collected from traps the next morning. The experiment was replicated on 15 July 2008 with treatments re-randomized, and using fresh females.

Dose-response trials with the synthetic pheromone were conducted in both southern California and Idaho. At SRPER in California, five traps in each of the four blocks (see above) were assigned randomly to lures containing 0 , $10,32,100$, and $320 \mu \mathrm{g}$ of 3,5-dimethyldodecanoic acid in $100 \mu \mathrm{l}$ of hexane. The experiment was set up on 4 July 2008 and run for three consecutive days (treatments rotated each day). In Idaho, we conducted two dose-response experiments, each in the same four hop yards. In the first (high-dose) experiment, traps were baited with $0,10,100$, 1000 , or $10^{4} \mu \mathrm{g}$ of the synthetic mixture of isomers (in $100 \mu \mathrm{l}$ hexane) on 8 and 9 July 2008. The second (lowdose) experiment tested the responses of male beetles to 0 , $0.1,1,10$, and $100 \mu \mathrm{g}$ in $100 \mu \mathrm{l}$ hexane on 10 and 11 July 2008.

Statistics For laboratory bioassays, we compared the number of males that responded positively to treatments versus controls, or to one of the two enantiomers, with $\chi^{2}$ goodness-of-fit tests. For field experiments, differences between treatments in numbers of beetles captured were tested separately for $P$. californicus and $P$. lecontei with the nonparametric Friedman's test (blocking by replicate; PROC FREQ with CMH option; SAS Institute, 2001), because assumptions of analysis of variance were violated by heteroscedasticity (Sokal and Rohlf, 1995). We tested differences between pairs of means with the REGWQ means-separation test to control maximum experiment-wise error rates (SAS Institute, 2001). Replicates that captured fewer than three beetles across all treatments were dropped from the analyses for each species.

Voucher specimens of the two Prionus species have been submitted to the W. F. Barr Entomology Museum at the University of Idaho and the Entomology Research Museum at the University of California, Riverside.

\section{Results}

Identification of the Insect-produced Stereoisomer 3,5Dimethyldodecanoic acid, with two chiral centers, has four possible stereoisomers. The mixture of the four was separated cleanly into two GC peaks on an achiral DB-5 column, that corresponded to the syn $\left(3 R^{*}, 5 R^{*}\right)$ and anti $\left(3 R^{*}, 5 S^{*}\right)$ diastereomeric pairs of enantiomers (Rodstein et al., 2009). The corresponding methyl esters eluted in the same order as the parent acids and were also resolved to baseline, with the additional advantages that the peaks were more symmetrical and the retention times less variable than those of the parent acids. The retention times of the insect-produced acid and its methyl ester matched those of the later-eluting diastereomer of the synthesized acid and its methyl ester, respectively. These were proven to be the anti-diastereomers by comparing their retention times with those of anti $(3 S, 5 R)-3,5$ dimethyldodecanoic acid and its ester; as expected, the retention times of syn $(3 S, 5 S)$-dimethyldodecanoic acid and its ester matched those of the earlier eluting peaks in the synthetic mixtures of all four stereoisomers of the acid and their esters, respectively. However, we were not able to determine the absolute configuration of the insectproduced compound by analytical methods, because all attempts at resolving the methyl esters of the enantiomers on a chiral stationary phase GC column (Cyclodex-B) were unsuccessful. Thus, laboratory and field bioassays were used to indirectly determine the naturally-produced enantiomer.

Stereoselective Syntheses of Stereoisomers of 3,5Dimethyldodecanoic Acid (Fig. 1) Three of the four possible stereoisomers of 3,5-dimethyldodecanoic acid were synthesized in good stereoisomeric purity, using the copper-catalyzed asymmetric conjugate addition of alkylmagnesium bromides to $\alpha, \beta$-unsaturated methyl esters 
(Lum et al., 2008) as the key reaction for introducing each of the two chiral methyl groups. Thus, $(E)$-2-decenoic acid (1) was converted to the corresponding methyl ester (2) by treatment with $\mathrm{HCl}$ in methanol, generated in situ. The first chiral methyl group then was introduced by reaction of $\alpha, \beta$-unsaturated ester (2) with methylmagnesium bromide, with $\mathrm{CuI}$ and $(S)$-Tol-BINAP catalysis, to give methyl (S)-(-)-3-methyldecanoate (3). This compound was reduced to the corresponding aldehyde with DIBAL-H in hexane, followed by stabilized Wittig olefination in the same pot with methyl (triphenylphosphoranylidene) acetate to yield methyl $(S)-(-)-5$-methyl-2-dodecenoate as a mixture of $(Z)$ - and $(E)$-isomers. These were separable by flash chromatography, giving the geometrically pure methyl (2E,5S)-(-)-5-methyl-2-dodecenoate (4) required for the next step. $\alpha, \beta$-Unsaturated ester (4) then was subjected to the same copper-catalyzed asymmetric conjugate addition conditions with methylmagnesium bromide, $\mathrm{CuI}$, and $(R)$-Tol-BINAP, yielding methyl (3R,5S)-(-)-3,5dimethyldodecanoate (5). Hydrolysis of the ester with $\mathrm{KOH}$ in aqueous ethanol gave the free acid (6).

The enantiomeric $(3 S, 5 R)-(+)-3,5$-dimethyldodecanoic acid (10) was made in analogous fashion by the same sequence of reactions, but using the catalysts with the opposite configuration to those used in the first sequence. Thus, unsaturated ester (2) was reacted with methylmagnesium bromide, $\mathrm{CuI}$, and $(R)$-Tol-BINAP to give methyl $(R)$ (-)-3-methyldecanoate (7). DIBAL-H reduction and chain extension with methyl (triphenylphosphoranylidene) acetate yielded methyl (R)-(-)-5-methyl-2-dodecenoate (8). Asymmetric conjugate addition of compound $\mathbf{8}$ with methylmagnesium bromide, CuI, and (S)-Tol-BINAP yielded methyl $(3 S, 5 R)-(+)-3,5$-dimethyldodecanoate (9), which was hydrolyzed to give $(3 S, 5 R)-(+)-3,5$-dimethyldodecanoic acid (10).

Finally, reaction of methyl (2E,5S)-(-)-5-methyl-2dodecenoate (4) with methylmagnesium bromide, CuI, and $(S)$-Tol-BINAP, gave the diastereomeric methyl (3S,5S)-(-)-dimethyldodecanoate (11).

Laboratory Bioassays of Synthetic Pheromone In olfactometer bioassays, 18 of 22 male P. californicus (82\%) responded positively to $100 \mathrm{ng}$ of 3,5-dimethyldodecanoic acid, and 36 of 41 males (88\%) responded to $10 \mathrm{ng}$ (treatments different from 1:1 positive:negative responses for both: $\chi_{1,22}^{2}=21.8, P=0.003 ; \chi_{1,41}^{2}=23.4, P<0.001$, respectively). However, only 13 of $22(62 \%)$ males responded to $1 \mathrm{ng}$ of 3,5-dimethyldodecanoic acid (treatment not different from 1:1: $\chi_{1,21}^{2}=1.19, P=0.28$ ).

When equal doses of the two enantiomers were directly compared in olfactometer bioassays, 13 of 14 males (93\%) and 13 of 16 males $(81 \%)$ moved to the olfactometer arm baited with $(3 R, 5 S)$ - dimethyldodecanoic acid, at doses of
25 and $2.5 \mathrm{ng}$, respectively (treatments different from 1:1; $\left.\chi_{1,14}^{2}=10.3, P=0.001 ; \chi_{1,16}^{2}=6.25, P=0.012\right)$. Males showed a marginal positive response to $(3 R, 5 S)$ - over $3 S, 5 R$ dimethyldodecanoic acid at $0.25 \mathrm{ng}$ (8 of 10 males [80\%]; $\left.\chi_{1,10}^{2}=3.6, P=0.058\right)$. Males did not respond to either 0.25 or $2.5 \mathrm{ng}$ of $(3 S, 5 R)$-dimethyldodecanoic acid when this enantiomer was tested against a solvent control (6 of 13 males [48\%] and 10 of 17 [59\%]: not different from $1: 1 ; \chi^{2}{ }_{1}$, ${ }_{25}=0.04, P=0.84 ; \chi_{1,17}^{2}=0.53, P=0.47$, respectively).

Field Bioassays of Synthetic Pheromones Traps in southern California baited with 3,5-dimethyldodecanoic acid, $(3 R, 5 S)$ dimethyldodecanoic acid, or $(3 S, 5 R)$-dimethyldodecanoic acid, captured a total of 100 male P. californicus and 23 male $P$. lecontei. No females of either species were caught. The numbers of male $P$. californicus and P. lecontei captured were strongly and similarly affected by experimental treatment (Friedman's $\mathrm{Q}_{3,28}=18.2, P<0.001, \mathrm{Q}_{3,16}=9.4, P=$ 0.025 , respectively). Male $P$. californicus responded strongly and equally to 3,5-dimethyldodecanoic acid and $(3 R, 5 S)$-dimethyldodecanoic, but showed little attraction to $(3 S, 5 R)$-dimethyldodecanoic acid or controls (Fig. 2). Male $P$. lecontei were most strongly attracted to $(3 R, 5 S)$ dimethyldodecanoic acid, showed intermediate attraction to 3,5-dimethyldodecanoic acid, and were not attracted to (3S,5R)-dimethyldodecanoic acid or controls (Fig. 2).

Traps baited with 3,5-dimethyldodecanoic acid, $(3 R, 5 S)$ dimethyldodecanoic acid, or live female $P$. californicus in Idaho captured a total of 252 male $P$. californicus, but no $P$. lecontei. Trap catches of male $P$. californicus again were affected by experimental treatment (Fig. 3; Friedman's $Q_{3,31}=23.4, P<0.001$ ). 3,5-Dimethyldodecanoic acid and $(3 R, 5 S)$-dimethyldodecanoic acid attracted similar numbers of males. Significantly fewer males were captured in traps baited with virgin females or in controls (Fig. 3). The latter

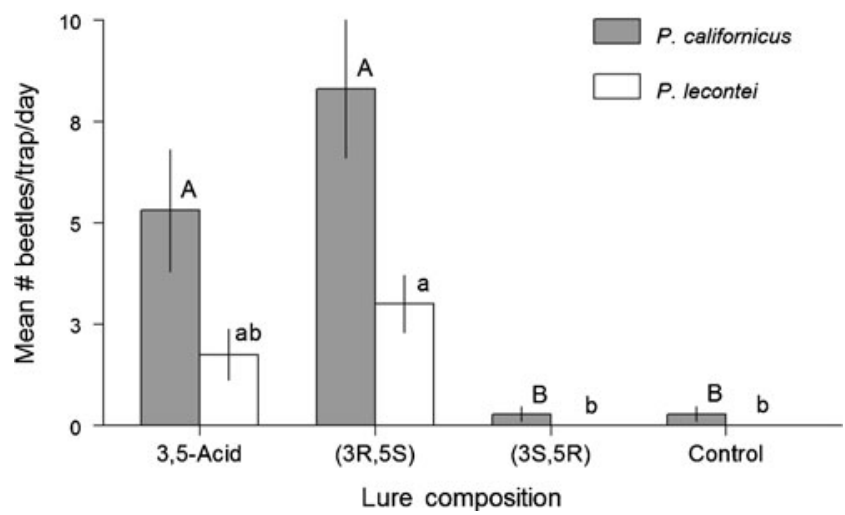

Fig. 2 Mean number ( \pm SE) of male Prionus californicus $(N=100)$ and Prionus lecontei $(N=23)$ captured in southern California by traps baited with 3,5-dimethyldodecanoic acid ("3,5-Acid"), $(3 R, 5 S)$ dimethyldodecanoic acid, (3S,5R)-dimethyldodecanoic acid, and solvent lures ("Control"). Bars with different letters of the same case are significantly different (REGWQ test, $P<0.05$ ) 


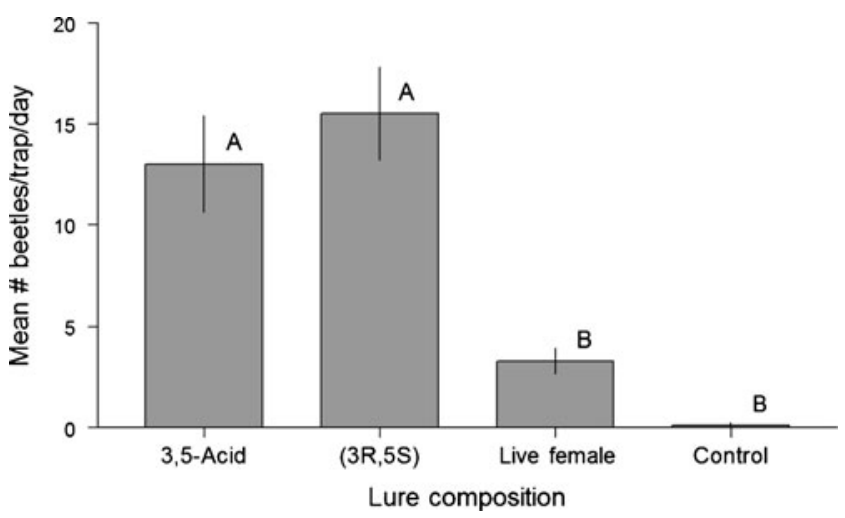

Fig. 3 Mean number $( \pm \mathrm{SE})$ of Prionus californicus males $(N=252)$ captured in Idaho by traps baited with racemic 3,5-dimethyldodecanoic acid ("3,5-Acid", $1 \mathrm{mg}),(3 R, 5 S)$-dimethyldodecanoic acid $(0.25 \mathrm{mg})$, a live female Prionus californicus, and control lures treated with solvent ("Control"). Bars with different letters are significantly different (REGWQ test, $P<0.05$ )

two treatments did not differ in the number of beetles captured (Fig. 3).

In the dose-response bioassay in southern California, traps captured totals of 62 male $P$. californicus and 44 male $P$. lecontei. There were too few replicates that captured three or more $P$. lecontei to allow a robust statistical analysis. For $P$. californicus, trap catch was affected by dose (Fig. 4, top; Friedman's $Q_{4,50}=17.2, P=0.002$ ), with only traps in the $320 \mu \mathrm{g}$ treatment capturing more beetles than control traps. The high- and low-dose trials for the dose-response bioassays in Idaho captured 145 and 139 male $P$. californicus, respectively, and the number of males captured was affected by pheromone dose in both trials (Fig. 4, bottom; Friedman's $Q_{4,30}=21.2, P<0.001, Q_{4,45}=$ $32.0, P<0.001$, respectively). The two trials were consistent in capturing no beetles in control traps, and in traps baited with doses higher than $100 \mu \mathrm{g}$ (high-dose trial) or $10 \mu \mathrm{g}$ (low-dose trials) capturing more male $P$. californicus than control traps (Fig. 4, bottom). The number of males captured did not differ for pheromone doses of $0.1 \mathrm{mg}$ and higher in the high-dose trial, but in the low-dose trial, the number of males captured was higher for $100 \mu \mathrm{g}$ than for 1 and $10 \mu \mathrm{g}$ (Fig. 4, bottom).

\section{Discussion}

Identification and Synthesis of the Stereoisomers To verify the identification of the basic carbon skeleton of the pheromone, we previously had developed a nonstereoselective synthesis of the mixture of all four stereoisomers of 3,5-dimethyldodecanoic acid (Rodstein et al., 2009). Although the diastereomers or their methyl esters were readily separable on GC, we did not know which diastereomer corresponded to which peak. Thus, we stereoselectively synthesized three of the four possible stereoisomers, with the goal of first determining the relative stereochemistry of the methyl groups in the pheromone (i.e., the correct diastereomer), followed by determination of the natural enantiomer. With these standards in hand, we showed unequivocally that the insect-produced compound was the anti diastereomer. Although we were not able to resolve the enantiomers (as their methyl esters) on a chiral stationary phase GC column, the question as to which enantiomer was produced by the insects was resolved indirectly by the results of both laboratory and field bioassays, in which $(3 R, 5 S)$-3.5-dimethyldodecanoic acid was highly attractive to male beetles, whereas its enantiomer was virtually inactive.

The enantiomers of 3,5-dimethyldodecanoic acid were synthesized using the asymmetric conjugate addition developed by Lum et al. (2008) to place each of the chiral methyl groups. Use of this method has several
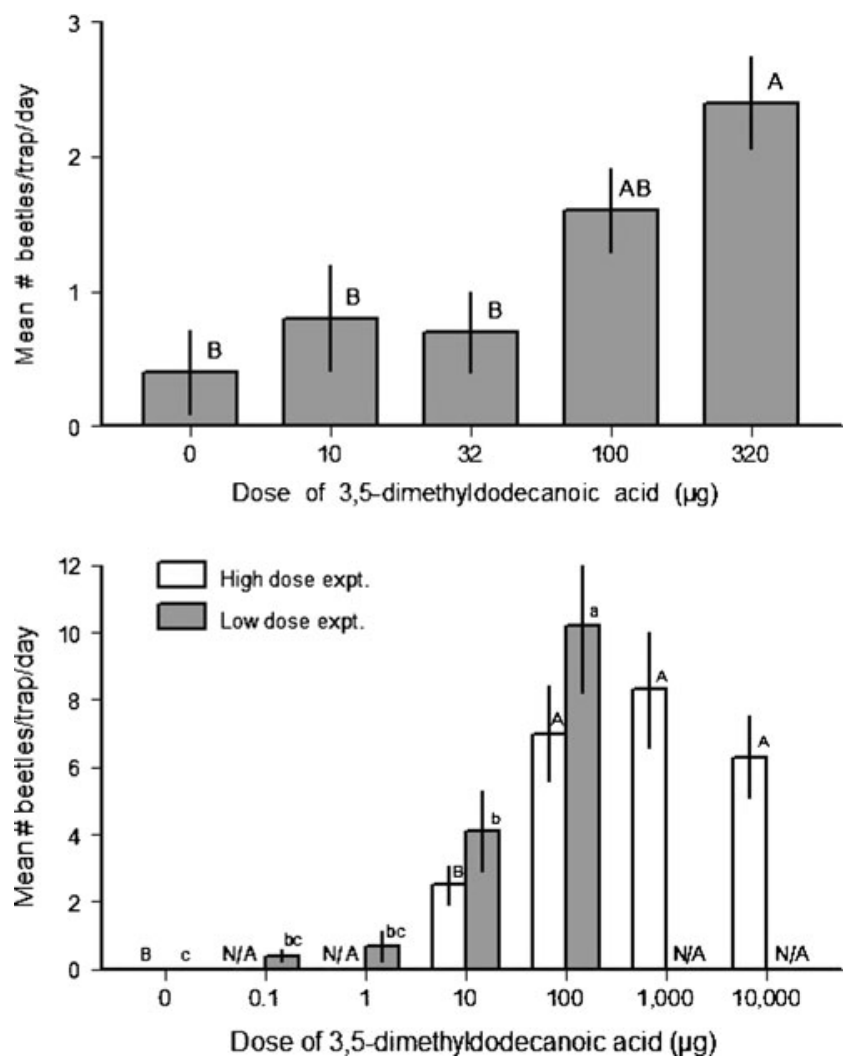

Fig. 4 Mean number ( \pm SE) of adult male Prionus californicus captured in traps baited with various doses of racemic 3,5dimethyldodecanoic acid. Top; bioassays conducted in California $(N=$ 62); Bottom: bioassays conducted in Idaho testing high and low doses $(N=145$ and 139 males, respectively). N/A indicates dosages that were not included in a particular experiment. Bars with different letters of the same case are significantly different (REGWQ test, $P<0.05$ ) 
advantages. First, each conjugate addition step proceeds with high enantioselectivity, yielding products of known absolute configuration. Second, either enantiomer is equally accessible simply by changing the chiral ligand in the reaction (i.e., $(R)$-Tol-BINAP or $(S)$-Tol-BINAP). Third, the reaction can be applied readily in iterative fashion, so that the same reaction can be used to place each methyl group sequentially. However, this route was not without minor problems. For example, it proved to be critically important to use the $\alpha, \beta$-unsaturated methyl esters for the addition reaction; use of the analogous ethyl esters resulted in a decrease in stereoselectivity.

During the course of these reactions, all direct attempts at determining the enantiomeric purities of intermediates, final products, or several derivatives thereof, were unsuccessful. Thus, enantiomeric pairs of methyl esters $\mathbf{3}$ and 7, $\mathbf{4}$ and $\mathbf{8}$, and $\mathbf{5}$ and $\mathbf{9}$ were not resolved on the Cyclodex-B column, nor were the corresponding alcohols from reduction of these esters resolved. Furthermore, the enantiomers of 1-bromo-2methylnonane, derived from hydrolysis of methyl 3methyldecanoate followed by decarboxylative halogenation by the Cristol-Firth modification of the Hunsdieker reaction (Cristol and Firth, 1961), failed to resolve on this column, and the analogous enantiomers of 1-bromo-2,4dimethylundecane also were not resolved. Whereas the diastereomeric purities of the $(3 S, 5 R)-,(3 R, 5 S)-$, and $(3 S, 5 S)$-stereoisomers were $92.5,90.7$, and $97.5 \%$, respectively, as determined by the ratios of their GC peak areas, the enantiomeric purities must necessarily be much higher because almost all of the enantiomeric impurity formed in the first asymmetric reaction is converted to a diastereomer of the desired product in the second asymmetric reaction. Similarly, any loss of stereospecificity in the second asymmetric reaction results in a diastereomer of the desired product rather than the undesired enantiomer.

Bioassay Results The fact that only males of P. californicus were attracted to synthetic pheromone in field bioassays confirmed that $(3 R, 5 S)$-dimethyldodecanoic acid is a female-produced sex pheromone for this species. This compound does not function as an aggregation pheromone, as appears to be the case for the male-produced pheromone of many species in the subfamilies Aseminae and Cerambycinae (see Introduction). Male P. californicus were quite sensitive to the pheromone, as indicated by the $0.25-2.5 \mathrm{ng}$ response threshold in the olfactometer bioassays. This level of sensitivity is consistent with the strong responses of males to live females, dead females, and even their excised ovipositors, demonstrated in an earlier study (Cervantes et al., 2006). The response was entirely enantiospecific: males showed no response in laboratory or field studies to the unnatural enantiomer, (3S,5R)-dimethyldodecanoic acid. There was no indication that any of the unnatural stereoisomers inhibited behavioral responses to the insect-produced stereoisomer, with male $P$. californicus responding as well to the mixture of the four stereoisomers as they did to $(3 R, 5 S)$-dimethyldodecanoic acid. This strong attraction to the mixture of stereoisomers will be useful for commercial development of the pheromone because it circumvents the need for an expensive chiral synthesis.

Dose-response bioassays in the field demonstrated that males responded to doses of synthetic pheromone as low as $10 \mu \mathrm{g}$ when dispensed from plastic bag dispensers, consistent with their responses to minute quantities of pheromones in olfactometer bioassays. As doses increased, the numbers of males captured reached a plateau midway through the series, with doses $>100 \mu \mathrm{g}$ attracting similar numbers of males. Traps baited with the synthetic pheromone captured greater numbers of males than did the caged females used as positive controls. In previous studies, we demonstrated that traps baited with live females capture large numbers of males when not competing with pheromone traps (Cervantes et al., 2006). Taken together, these results suggest that the pheromone of this species consists of $(3 R, 5 S)$-dimethyldodecanoic acid as a single component, despite the fact that extracts from females contain both homologs (with longer chains) and analogs (methyl esters of the acids) of 3,5-dimethyldodecanoic acid (Rodstein et al., 2009).

Our capture of male $P$. lecontei in southern California in traps baited with the pheromone of $P$. californicus was unexpected, and suggests that females of $P$. lecontei also produce a sex pheromone that contains $(3 R, 5 S)$ dimethyldodecanoic acid. To date, we have not been able to confirm this, because all attempts at collecting female $P$. lecontei at light or light traps have been fruitless. The dose-response profile of male $P$. lecontei to $(3 R, 5 S)$ dimethyldodecanoic acid was similar to that of male $P$. californicus, which further suggests that this compound is a major, if not the only, component of the pheromones of both species. What remains unclear is how these congeners maintain reproductive isolation, because they are sympatric in at least some areas of southern California (Monné and Hovore, 2005), and clearly have overlapping annual flight periods (i.e., substantial numbers of males of both species were caught during field trials in midsummer). It is possible that one or more of the other components in the crude extracts from $P$. californicus females may serve to inhibit the responses of male $P$. lecontei. This possibility remains to be tested once the other components have been synthesized and are available for follow-up field trials. 
The complete absence of P. lecontei in Idaho may have been due to our sampling only in hop yards, or because southwest Idaho lies outside the geographic range of $P$. lecontei. Both P. lecontei and P. californicus are distributed in western North America, but there is little information available about their altitudinal distribution, beyond the fact that $P$. californicus occurs in the Rocky Mountains, whereas $P$. lecontei appears to be limited to a more western distribution (Linsley, 1962). Overall, these results indicate that traps baited with 3,5-dimethyldodecanoic acid will be an ideal tool to characterize the distribution and abundance of these congeners over their entire ranges.

The strong attraction of male $P$. californicus to even small amounts of synthetic pheromone also suggests that this compound has potential for monitoring and managing this species in agricultural and horticultural situations, where it is an important pest. As described above, $P$. californicus is one of the most important pests of hop in the Pacific Northwest. In addition, P. californicus and $P$. lecontei are chronic pests of a variety of tree crops, including apples and stone fruits (Solomon, 1995). We currently are evaluating potential uses of the pheromone for control of P. californicus in hop production by mating disruption or mass trapping.

Acknowledgements We thank Wittko Franke for helpful discussions during identification of the pheromone, Steven Lingafelter for taxonomic assistance, and Carole Bell at Santa Rosa Plateau Ecological Reserve for permitting access to field sites. The project was supported by the Hop Research Council, USDA/Western Region IPM grant number 207-03623 (to JDB, JGM, and LMH), and the National Research Initiative (NRI) Arthropod and Nematode Biology and Management Program of the USDA Cooperative State Research, Education and Extension Service (CSREES) grant number 2006-3530217457 (to JGM and LMH), and the Alphawood Foundation (to LMH).

Open Access This article is distributed under the terms of the Creative Commons Attribution Noncommercial License which permits any noncommercial use, distribution, and reproduction in any medium, provided the original author(s) and source are credited.

\section{References}

Barbour, J. D., Cervantes, D. E., Lacey, E. S., and Hanks, L. M. 2007. Calling behavior in the primitive longhorned beetle Prionus californicus Mots. J. Insect Behav. 19:623-629.

BENHAM, G. S., JR., and FARRAR, R. J. 1976. Notes on the biology of Prionus laticollis (Coleoptera: Cerambycidae). Can. Entomol. 108:569-576.

Bense, U. 1995. Longhorn Beetles. Illustrated Key to the Cerambycidae and Vesperidae of Europe. Margraf Verlag, Weikersheim, Germany.

Bishop, G. W., Blackmer, J. L., and BAird, C. R. 1984. Observations on the biology of Prionus californicus Mots. on hops, Humulus lupulus L., in Idaho. J. Entom. Soc. British Columbia 81:20-24.
Boyer, F.-D., Malosse, C., Zagatti, P., and Einhorn, J. 1997. Identification and synthesis of vesperal, the female sex pheromone of the longhorn beetle Vesperus xatarti. Bull. Soc. Chim. France 134:757-764.

Cervantes, D. E., Hanks, L. M., Lacey, E. S., and Barbour, J. D. 2006. First documentation of a volatile sex pheromone in a longhorned beetle (Coleoptera: Cerambycidae) of the primitive subfamily Prioninae. Ann. Entomol. Soc. Am. 99:718-722.

Cristol, S. J., and FIRTH, W. C., JR. 1961. Convenient synthesis of alkyl halides from carboxylic acids. J. Org. Chem. 26:280.

DonG, K. Z., and YANG, X. K. 2003. Progress in classification of higher taxa of the Cerambycidae. Entomol. Knowledge 40:211217. (in Chinese)

EDWARDS, J. S. 1961. Observations on the ecology and behavior of the huhu beetle, Prionoplus reticularis White (Col. Ceramb.). Trans. R. Soc. New Zealand 88:733-741.

Gemeno, C., and Schal, C. 2003. Sex pheromones of cockroaches, pp. 179-247, in R. T. Cardé and J. G. Millar (eds.). Advances in Insect Chemical Ecology. Cambridge University Press, NY.

Gwynne, D. T., and Hostetler, B. B. 1978. Mass emergence of Prionus emarginatus (Say) (Coleoptera: Cerambycidae). Coleopterists Bull. 32:347-348.

Hovore, F. T. 1981. Two new species of Prionus (Homaesthesis) from the southwestern United States, with notes on other species (Coleoptera: Cerambycidae). Coleopterists Bull. 35:453-457.

Lacey, E. S., Millar, J. G., Moreira, J. A., and HanKs, L. M. 2009. Male-produced aggregation pheromones of the cerambycid beetles Xylotrechus colonus and Sarosesthes fulminans. J. Chem. Ecol. 35:733-740.

Leal, W. S., Bento, J. M. S., Vilela, E. F., and Della Lucia, T. M. C. 1994. Female sex pheromone of the longhorn beetle Migdolus fryanus Westwood: $N$-(2'S)-methylbutanoyl 2-methylbutylamine. Experentia 50:853-856.

Linsley, E. G. 1962. The Cerambycidae of North America Part II. Taxonomy and classification of the Parandrinae, Prioninae, Spondylinae, and Aseminae. Univ. Calif. Publ. Entomol. 19:1-107.

Linsley, E. G., and ChemsaK, J. A. 1997. The Cerambycidae of North America, Part VIII: Bibliography, index, and host plant index. Univ. Calif. Publ. Entomol. 117:1-534.

LuM, T. K., WANG, S. Y., and LOH, T. P. 2008. A highly catalytic asymmetric conjugate addition: Synthesis of the C14-C20 fragment of antibiotic TMC-151A, siphonarienal and siphonarienone. Org. Lett. 10: 761-764.

Millar, J. G., Hanks, L. M., Moreira, J. A., Barbour, J. D., and LACEY, E. S. 2009. Pheromone chemistry of cerambycid beetles. pp. 52-79, in K. Nakamura and J. G. Millar (eds.). Chemical Ecology of Wood-Boring Insects. Forestry and Forest Products Research Institute, Ibaraki, Japan.

Monné, M. A., and Hovore, F. T. 2005. Checklist of the Cerambycidae (Coleoptera) of the Western Hemisphere. BioQuip Publications, Rancho Dominguez, CA.

NAPP, D. S. 1994. Phylogenetic relationships among the subfamilies of Cerambycidae (Coleoptera - Chrysomeloidea). Rev. Bras. Entomol. 38:265-419.

Ray, A. M., Swift, I. P., Moreira, J. A., Millar, J. G., and Hanks, L. M. 2009a. (R)-3-hydroxyhexan-2-one is a major pheromone component of Anelaphus inflaticollis (Coleoptera: Cerambycidae). Environ. Entomol. 38:1462-1466.

Ray, A. M., Millar, J. G., Swift, I. P., Barbour, J. D., McElfresh, J. S., and HANKS, L. M. 2009b. Male-produced aggregation pheromone of the cerambycid beetle Rosalia funebris. J. Chem. Ecol. 35:96-103.

Rodstein, J., McElfresh, J. S., Barbour, J. D., Ray, A. M., HANKS, L. M., and Millar, J. G. 2009. Identification and synthesis of a female-produced sex attractant pheromone for the 
cerambycid beetle Prionus californicus. J. Chem. Ecol. 35:590600 .

Rotrou, P. 1936. Le Cyrtognathus forficatus F. ses Moeurs. Bull. Soc Sci. Nat. Maroc. 16:246-251.

Santos Ferreira, G. W. 1980. The Parandrinae and the Prioninae of Southern Africa (Cerambycidae, Coleoptera). Mem. Nasionale Mus. Suid-Afrika 13:1-335.

SAS InstituTE. 2001. SAS/STAT User's Guide for Personal Computers, Release 8.01. SAS Institute, Cary, NC.

Silk, P. J., Sweeney, J., Wu, J., Price, J., Gutowski, J. M., and Kettela, E. G. 2007. Evidence for a male-produced pheromone in Tetropium fuscum (F.) and Tetropium cinnamopterum (Kirby) (Coleoptera: Cerambycidae). Naturwissenschaften 94:697-701.

SOKAL, R. R., and RoHLF, F. J. 1995. Biometry, 3rd edn. Freeman, New York, NY.

Solomon, J. D. 1995. Guide to insect borers of North American broadleaf trees and shrubs. U.S. Dept. Agric. For. Serv. Agric. Handbook 706, Washington, DC.

SuMmerLAND, S. A. 1932. The tile-horned prionus as a pest of apple trees. J. Econ. Entomol. 25:1172-1176.

ThORNHILl, R., and AlCOCK, J. 1983. The Evolution of Insect Mating Systems. Harvard University Press, Cambridge, MA. 